\title{
Optimism as Predictor of Psychological Well Being among
}

\section{Adolescents}

\author{
Farzana Parveen $^{1}$, Prof Shahina Maqbool ${ }^{2}$, Dr. Shah Mohd Khan ${ }^{3}$
}

\section{ABSTRACT}

Optimism is associated with positive outcomes in relationships in general, possibly as a result of processes that promote and maintain Psychological Well-being. The aim of this study was to investigate the relationship between Optimism and Psychological Well being. It also investigated the difference between Hindu and Muslim, male and female Adolescents on Psychological WellBeing and Optimism. For this study 120 Adolescents were selected from Aligarh Muslim University, comprises 60 Hindu male \& female and 60 Muslim male \& female through random sampling. Pearson product moment correlation was also used for measuring the relationship between Optimism and Psychological Well-being, t-test was used to know the difference between male and female \& Hindu and Muslim adolescents. Result shows that there is significant positive correlation between optimism and psychological well-being and there was insignificant difference between male and female adolescents on optimism and psychological well-being.

Keywords: Optimism, Psychological Well-being, Adolescents

In the recent past, a large number of psychologists have been interested in overlapping areas like quality of life, life satisfaction, happiness, subjective well-being, psychological well-being etc. The focused efforts in these areas were partly responsible for the emergence of positive psychology. Dispositional Optimism is the ability to look at the brighter side of the life and can maintain complete Psychological well-being. This study helps us to investigate the relationship and difference between Hindu and Muslims male and female adolescents.

\footnotetext{
${ }^{1}$ Research Scholar, Department of Psychology, Aligarh Muslim University, Aligarh, India

${ }^{2}$ Professor, Department of Psychology, Aligarh Muslim University, Aligarh, India

${ }^{3}$ Associate Professor, Department of Psychology, Aligarh Muslim University, Aligarh, India

*Responding Author

(C) 2016, F Parveen, S Maqbool, M Khan; licensee IJIP. This is an Open Access Research distributed under the terms of the Creative Commons Attribution License (http://creativecommons.org/licenses/by/2.0), which permits unrestricted use, distribution, and reproduction in any Medium, provided the original work is properly cited.
} 


\section{Optimism as Predictor of Psychological Well Being among Adolescents}

\section{Optimism:}

Dispositional Optimism is a global expectation that more good things than bad will happen in the future. Optimism assumes a measure of hope in one's approach to life. Optimism is rather the ill defined term that has been used to define a range of different feeling and experiences and dispositions in various social and historical context .Optimism is a common human experience, however, it can take on a variety of forms depending on individual circumstances and particular social contexts. It is often combined with (or restrained by) varying degrees of realism, pragmatism, fatalism and even pessimism. Our ideas about optimism, and the extent to which we think optimistically, are formed both individually according to our personal idiosyncrasies and socially in relation to the social worlds in which we live.

As individuals and in groups we learn on the one hand to be more wary of some types of risk and on the other to be more optimistic about particular outcomes or eventualities. Given its importance as part of the human condition and its relevance to issues of individual and psychological well-being, optimism has also received a considerable amount of attention among scholars and academics from a range of disciplines. Over time, this has led to a variety of understandings of how optimism can be defined. As in popular culture, scholarly debate often portrays optimism either as a positive trait or, alternatively as a kind of unhealthy self-deception. Importantly, we look not only at optimism at an individual level but also at its social aspects. Optimism has been generally regarded as cognitive variable (Scheier \& carver 1987).

Scheier and Carver (1985) have defined optimists as people who "generally believe that good rather than bad things will happen to them" Dispositional optimism, or the generalized expectancy for positive outcomes, is a particularly interesting resource variable in the present context for three reasons.

(1)First, optimistic persons might be more inclined than pessimists to derive a sense of benefit from adversity (Tennen \& Affleck, 1998).

(2)Second, it is known that optimism is not related to rigid patterns of coping strategies, irrespective of stressor type. In fact, optimism is related to flexible use of adaptive coping strategies with regard to the controllability of stressors (Solberg Nes \& Segerstrom, 2006).

(3)Third, optimism is considered a predictor of perceived capability to manage the demands of a potentially traumatic event (Benight \& Bandura, 2004).

\section{Psychological Well-Being:}

Now a day we find a completely different scenario among the male and the female school going students. They are surrounded by many kinds of problems, not only in relation to the extremely 


\section{Optimism as Predictor of Psychological Well Being among Adolescents}

high pace of the ongoing competition but also personal issues causing not physical but also psychological weaknesses. The psychological well-being of the students gets affected in such relations and situations. Psychological well-being, broadly defined as happiness, life satisfaction, and self-growth represents one of the most important aspects of efficient psychological functioning. Indeed, much research reveals that happy people experience a number of benefits ranging from physical health to better relationships to high-level performance (e.g., Huppert 2009; Lyubomirsky et al. 2005). Psychological well-being is usually conceptualized as some combination of positive affective states such as happiness (the hedonic perspective) and functioning with optimal effectiveness in individual and social life (the eudemonics perspective) (Deci \& Ryan 2008).

Psychological Well-being indicates physical and mental wellness. Sinha (1990) has stated that psychological well-being is difficult to define. It has been taken to consist of discomfort or desirability and from any disturbance of mental functions. It is a somewhat malleable concept which has to do with people's feelings about everyday life activities. Such feelings may range from negative mental states or psychological strains such as anxiety, depression, frustration, emotional exhaustion unhappiness, dissatisfaction to a state which has been identified as positive mental health (Jahoda, 1958; Warr, 1978).

Ryff (2005) reported that measures of psychological well-being have little theoretical grounding, despite an extensive literature on the contours of positive functioning. Aspects of well-being derived from the literature on self-acceptance, positive relations with others, autonomy, environmental mastery, purpose in life, and personal growth were operationalised. Three hundred and twenty-one men and women, divided among young, middle-aged, and older adults, rated themselves on these measures along with six instruments prominent in earlier studies (i.e., affect balance, life satisfaction, self-esteem, morale, locus of control, depression). Results revealed that positive relations with others, autonomy, purpose in life, and personal growth were not strongly tied to prior assessment indexes.

\section{Objectives:}

(1) To investigate the relationship between Optimism and Psychological Well-Being on Adolescents.

(2) To find out Difference between Male and Female Adolescents on Psychological Well-Being and Optimism.

(3) To find out Difference between Hindu and Muslim Adolescents on Psychological WellBeing and Optimism. 


\section{METHODOLOGY}

\section{Sample:}

The participants of the present study comprise 120 Adolescents. It includes 60 males and 60 females, 30 each male Hindu \& Muslim, 30 female Hindu \& Muslim of 13 to 16 years of age from schools of Aligarh Muslim University. All of them are studying in $11^{\text {th }} \& 12^{\text {th }}$ class.

\section{Tools:}

\section{The Life Orientation Test:}

The life Orientation Test - Revised (Scheier \& Carver, 1985) introduced their index of Optimism as including positive ("I am always Optimistic about my future") and negative ("rarely count on good things happening to me”) expectancies. It is a 10 item questionnaire with reversed scoring. The LOT-R has displayed acceptable internal consistency (alpha of 0.78) and its test- retest correlation is 0.68 to 0.79 for intervals of 4 to 28 months (Scheier \& Carver, 1985).

\section{Psychological Well-Being Scale:}

This scale is constructed and standardized by Sudha Bhogale and Jai Prakash (1995) the scale consists of 27 statements. For each statement responses are given in two forms i.e. Yes or No. The scoring is done as per the manual and one who scores higher is said to have higher wellbeing and vice-versa.

\section{Procedure:}

The researcher, we approached all the participants through the school's administration. Before starting the procedure, we established good rapport with the participants and took them into confidence and make them sure about the confidentiality of their responses. We took their consent before distribution of all the questionnaires among them. We gave them instructions as printed on questionnaires.

\section{RESULT}

\section{Statistical Analysis:}

To compare Hindu and Muslim Adolescents and Male and Female Adolescents on psychological well-being and Optimism we used independent t-test, and to find out the relationship between psychological well-being and Optimism, Pearson Product Moment Coefficient of Correlation. Following tables show the result. Determined results are discussed in fallowing paragraphs. 
Table no-1: Descriptive Statistics And Correlation Between Optimism And Pwb

\begin{tabular}{|c|c|c|c|c|}
\hline VARIABLES & $\mathbf{N}$ & MEAN & SD & $\mathbf{r}$ \\
\hline $\begin{array}{l}\text { OPTIMISM } \\
\text { PSYCHOLOGICAL WELL-BEING }\end{array}$ & 120 & $\begin{array}{l}14.89 \\
16.40\end{array}$ & $\begin{array}{l}2.953 \\
2.485\end{array}$ & $.325^{* *}$ \\
\hline
\end{tabular}

$\mathrm{r}=0.15(\mathrm{p}<.05) ; \mathrm{r}=0.22(\mathrm{p}<.01)$

Table no- 1 shows r correlation between Optimism and Psychological Well-being is .325 which is significant at 0.01 level of significance. It can be inferred that there is significant positive correlation between Optimism \& Psychological Well-being. In other words, Optimism is increases so as PWB is also increases and vice-versa.

Table No- 2: Optimism \& Psychological Well Being: Gender

\begin{tabular}{|c|c|c|c|c|c|c|}
\hline DOMAIN & N & MEAN & SD & $\begin{array}{c}\text { Std. } \\
\text { Error of } \\
\text { Mean }\end{array}$ & t & p \\
\hline $\begin{array}{c}\text { MALIMISM } \\
\text { FEMALE }\end{array}$ & 60 & 14.38 & 2.681 & .346 & & \\
\hline PWB & 15.40 & 3.142 & .406 & -1.907 & .05 \\
& & & & & & \\
\hline FEMALE & 60 & 16.60 & 2.465 & .318 & -.881 & .380 \\
\hline
\end{tabular}

$\mathrm{t}=1.67(<.05) ; \mathrm{t}=2.39(\mathrm{p}<.01)$ one tailed

Table no-2 shows that the mean score of Optimism for Male and Female Adolescents are 14.38 \& 15.40 respectively and t-value on Optimism was -1.907 which is significant at 0.05 level of significance. The $\mathrm{p}$ value indicates that there is a significant difference between Male and Female Adolescents on the Optimism. The mean of female adolescents on optimism was high in comparison to male. It can be inferred that the life orientation of female is higher than male.

The mean scores of Psychological Well-being for Male and Female Adolescent are 16.20 and 16.60 respectively and t- value -.881 which is not-significant at 0.05 level of significance. It indicates that there is insignificant difference between Male and Female Adolescents on Psychological Well-being also. The mean score for female adolescents was high on optimism 


\section{Optimism as Predictor of Psychological Well Being among Adolescents}

and psychological well-being in comparison to male. It can be inferred that PWB is higher in case of female than male adolescents.

Table No-3: Optimism And Psychological Well-Being: Religion

\begin{tabular}{|c|c|c|c|c|c|c|}
\hline DOMAIN & $\mathbf{N}$ & MEAN & SD & $\begin{array}{l}\text { Std. } \\
\text { Error of } \\
\text { Mean }\end{array}$ & $\mathbf{t}$ & $\mathbf{p}$ \\
\hline $\begin{array}{c}\text { HINDU } \\
\text { OPTIMISM } \\
\text { MUSLIM }\end{array}$ & $\begin{array}{l}60 \\
60\end{array}$ & $\begin{array}{l}14.48 \\
15.30\end{array}$ & $\begin{array}{l}2.765 \\
3.099\end{array}$ & $\begin{array}{l}.357 \\
.400\end{array}$ & -1.523 & .130 \\
\hline $\begin{array}{ll} & \text { HINDU } \\
\text { PWB } & \\
& \text { MUSLIM }\end{array}$ & $\begin{array}{l}60 \\
60\end{array}$ & $\begin{array}{l}16.00 \\
16.80\end{array}$ & $\begin{array}{l}2.178 \\
2.717\end{array}$ & $\begin{array}{l}.281 \\
.351\end{array}$ & -1.779 & .078 \\
\hline
\end{tabular}

$\mathrm{t}=1.67(<.05) ; \mathrm{t}=2.39(\mathrm{p}<.01)$ one tailed

Table no-2 shows mean scores of Hindu and Muslim Adolescents on Optimism and Psychological well-being. The mean scores of Hindu and Muslim adolescents on optimism are 14.48 and 15.30 respectively and $t$ value is -1.523 . The mean scores of Hindu and Muslim adolescents on Psychological Well-being are16.00 and 16.80 respectively and the t-value is 1.779, there is no significant difference between Hindu and Muslim adolescents on Optimism and Psychological well-being. However, mean scores for Muslim adolescents was high on optimism and psychological well-being in comparison to Hindu.

\section{DISCUSSION}

The study was conducted to compare Hindu and Muslim, Male and Female adolescents on optimism and psychological well-being and to assess the impact of optimism on psychological well-being. Findings of the present study are discussed in the fallowing paragraph.

There was insignificant difference between Male and Female Adolescents on Optimism and Psychological well-being. Male adolescents scored lower on Optimism and psychological well being than Female, which shows that Females are more optimistic and psychologically healthy than Males and that the experimental evidence suggests that positive emotions are valuable because they foster positive perceptions of self and others, sociability, altruism, effective conflict resolution skills, and physical health (Lyubomirsky, King, \& Diener, 2005). Likewise, longitudinal research shows that happiness is associated with positive outcomes such as people having superior mental and physical health, greater longevity, more satisfying relationships, and being more fulfilled and productive at work (Lyubomirsky et al., 2005). Gaining greater insight 


\section{Optimism as Predictor of Psychological Well Being among Adolescents}

into positive emotions and their antecedents is crucial, given that positive emotions can exist independently from negative emotions (Ryff et al., 2006) and efforts to decrease negative emotions will not automatically result in increased positive emotions (see Schimmack, 2008 for a review). Research has begun to explore how positive emotions, which are typically short-lived, have such powerful effects in people's lives. Fredrickson's (2001) broaden-and-build theory emphasizes that positive emotions enable people to thrive because they momentarily broaden their attention and perspective to help them discover and build cognitive, psychological, social, and physical resources. Thus, it seems that positive emotions not only increase satisfaction and well-being in the moment, but also help people build resources that lead to experiencing life as more satisfying and fulfilling in the long term.

The first objective was to know the relationships between Hindu and Muslim Adolescents on Optimism and Psychological Well-being and the result shows that there is positive correlation. Here we found significant difference between Hindu and Muslim Adolescents on Optimism and Psychological well-being that means there is positive correlation between them. The relationships between optimism and psychological well-being have been observed in case studies as well as longitudinal studies (Wrosch and Scheier, 2003). From Coward and Reed (1996)'s viewpoint, psychological well-being is defined as a sense of feeling healthy leading to a complete awareness of personal integrity which also includes spiritual elements of life.

The present findings are consistent with previous research on optimism among adolescents (Chang \& Sanna, 2003; Lai, 2009), and lend support to the prediction that students reporting high level of optimism would be less likely to complain about somatic symptoms, compared to those reporting low levels of optimism. This finding is of interest because few prospective studies among senior high school students have reported significant effects of optimism on later symptomatology. A possible explanation may be that optimism influences physical well- being and mental well-being by fostering adaptive behaviors and cognitive responses that are associated with greater flexibility, problem-solving capacity and a more realistic appraisal of negative information.

Here the second objective shows that on Optimism and Psychological Well-being Female adolescents scored higher than Male Adolescents, that the result shows that Female Adolescents are more positive towards their goal they are mentally and psychologically healthy than Male Adolescents. The studies by R. Singh and Dhyani (2013), S. Singh and Mishra (2014), and Hasnain, Wazid, and Hasan (2014) found no significant gender differences on optimism/pessimism. However, Naresh Kumar (2012) found females to be more optimistic, whereas Vijayshri (2015) found females to be more pessimists. Thus the findings on gender difference in optimistic/pessimistic attitudes are a bit inconsistent. 


\section{Optimism as Predictor of Psychological Well Being among Adolescents}

The studies relating optimism/pessimism with well-being yielded comparatively a clear picture. There is substantial evidence that optimists use different coping strategies than do pessimists and that these coping differences contribute to the positive association between optimism, better adjustment and well being. (Stanton \& Snider, 1993; Carver, Scheier, \& Weintraub, 1989). Optimists possess more extensive and supportive social networks, and report longer friendship than do pessimists; the social networks influence psychological wellbeing by operating as a stress buffer (Cohen \& Wills, 1985). Coulter's (1999) review, covering medical field, also indicates the association between pessimism and distress, and optimism and well-being. (Ferguson \& Goodwin, 2010) also found optimism to be a predictor of both subjective and psychological well-being. Thus psychological well-being and optimistic attitude appear to be positively associated. Akhter (2015) reported females to be higher on psychological well-being. In fact, this review would be considerably lengthened if the literature on gender differences in related areas like quality of life, happiness, subjective well-being etc. is included. To sum up, in general the studies indicate either the absence of gender differences or only small to medium gender differences in psychological well-being.

The third objective reveals that insignificant difference between Hindu and Muslim Adolescents on Optimism and Psychological well-being. Here Hindu scored lower than Muslim Adolescents on Optimism as well as on Psychological Well-being. That means Muslim adolescents are using more beneficial coping strength than Hindu Adolescents. And Muslim Adolescents may have the ability to control negative direction of their life through Namaz and through many spiritual elements.

\section{Acknowledgments}

The author appreciates all those who participated in the study and helped to facilitate the research process.

\section{Conflict of Interests}

The author declared no conflict of interests.

\section{REFERENCES}

Akhter, S. (2015). Psychological well-being in student of gender difference. The International Journal of Indian Psychology , 2 (4).

Carver, C. S., Scheier, M. F., \& Weintraub, J. k. (1989). Assessing coping strategies: A theoretically based approach. Journal of Personality and Social Psychology , 56 (2), 267-283.

Chang, E. C., \& Sanna, L. J. (2003). Experience of life hassles and psychological adjustment among adolescents: Does it make a differ-ence if one is optimistic or pessimistic? Personality and Individual Differences, 34, 867-879. doi:10.1016/S0191-8869(02)00077-6

Cohen, S., \& Willis, T. A. (1985). Stress, social support and the buffering hypothesis. Psychological Bulletine , 98 (2), 310-357. 


\section{Optimism as Predictor of Psychological Well Being among Adolescents}

Coulter, L. A. (1999). Optimism, coping and psychological well-being among people with advanced cancer. Dalhousie University, For the degree of Master of nursing, Halifax, Nova Scotia.

Coward, D. D., \& Reed, P. G. (1996). Self-Transcendence: a resource for healing at the end of life, Issues in Mental Health Nursing, 17(3), 275- 288.

Deci, E.L.\& Ryan , R.M.(2008). Hedonia , eudaimonia and Well-being .An introduction. Journal of Happiness studies, 9,1-11 doi: 10. 1007/s 10902-006-9018-1.

Ferguson, S. J., \& Goodwin, A. D. (2010). Optimism and well-being in older adults: The mediating role of social support and perceived control. The International Journal of Aging and Human Development , 71 (1), 43-68.

Fredrickson, B. L. (2001). The role of positive emotions in positive psychology: The broadenand-build theory of positive emotions. American Psychologist, 56, 218-226

Hasnain, N., Wazid, S. W., \& Hasan, Z. (2014). Optimism, hope, and happiness as correlates of psychological well-being among young adult assumes males and females. IOSR Journal of Humanities and Social Science, 19 (2), 44-51.

Honmore, M Jadhav; (2015). Psychological well-being , Gender and Optimistic Attitude among College Students. The International Journal of Indian Psychology , 3 (1).

Huppert FA (2009). Psychological well-being: Evidence regarding its causes and consequences. Applied Psychology: Health and Well-Being, 1, 137-164.

Jahoda, M. (1958). Current concepts of positive mental health. New York: Basic Books.

Kotar A. B. (2013) A Comparative study of psychological Well-being among arts and science college students. Acme International Journal of Multidisciplinary Research. Vol-1 IssueIX September

Lai, J. C. L. (2009). Dispositional optimism buffers the impact of daily hassles on mental health in Chinese adolescents. Personality and In-dividual Differences, 47, 247-249. doi:10.1016/j.paid.2009.03.007

Lyubomirsky S, King L, Diener E (2005). The benefits of frequent positive affect: Does happiness lead to success? Psychological Bulletin, 131, 803-855.

Lyubomirsky, S., King, L., \& Diener, E. (2005). The benefits of frequent positive affect: Does happiness lead to success? Psychological Bulletin, 131(6), 803-855. doi:10.1037/00332909.131.6.803.

Miller- Perrin C; Krumeri Mancuso, E. (2015) Faith from a positive Psychology Perspective X, 255 p. Hardcover ISBN : 978-94-017-9435-0

Murberg A.T. (2012)The influence of Optimistic expectation and negative life events on somatic symptoms aong adolescents: A one year perspective study. Vol-3 No-2, 123-127

NareshKumar. (2012). Emotional intelligence as related to optimistic-pessimistic attitude of B. Ed. teacher trainees. International Journal of Basic and Advanced Research , 1 (3), 53-56.

Ryff, C. D. (2005). Psychological well-being in adult life. Journal of Current Directions in Psychological Science, 4, 99-104

Ryff, C. D., Love, G., Urry, H. L., Muller, D., Rosenkranz, M. A., Friedman, E. M., \& .. . 


\section{Optimism as Predictor of Psychological Well Being among Adolescents}

Scheier, M. F., \& Carver, C. S. (1985). Optimism, coping, and health assessment and Mplications of generalized outcome expectancies. Health Psychology, 4, 219-247.

Schimmack, U. (2008). The structure of subjective well-being. In M. Eid \& R. Larsen (Eds.), The science of subjective well-being (pp. 97-123). New York: Guilford Press.

Singer, B. (2006). Psychological well-being and ill-being: Do they have distinct or mirrored biological correlates?. Psychotherapy And Psychosomatics, 75(2), 85-95. doi:10.1159/000090892.

Singh, R., \& Dhyani, A. (2013). Attitude towards life: A family environment perspective. International Conference on Social Science Research, ICSSR, (pp. 1547-1551). Penang, Malaysia.

Singh, S., \& Mishra, S. (2014). Optimism-pessimism among adolescents- A gender based study. International Journal of Science and Research (IJSR) , 3 (6), 1530-1532.

Souri H. Hasanirad T.(2011) Relatonship between Resilience , Optimism and Psychological Well-being in students of Medicine. Procedia- social and Behavioural Sciences 3015411544

Stanton, A., \& Snider, P. (1993). Coping with a breast cancer diagnosis: A prospective study. Health Psychology , 12 (1), 16-23.

V. Honmore, M. Jadhav (2015) Psychological Well-being, Gender and Optimistic attitude among college students. International Journal of Indian Psychology Vol 3 Issue 1, DIP:C00236V3I12015

Vijayashri. (2015). Life satisfaction influenced by optimistic and pessimistic attitude: A study of older adults. International Journal of Scientific Research , 4 (5), 728-731.

Warr, P.B. (1978). A study of psychological well-being. British Journal of Psychology, Vol.69, PP.111- 121.12

How to cite this article: F Parveen, S Maqbool, M Khan (2016), Optimism as Predictor of Psychological Well Being among Adolescents, International Journal of Indian Psychology, Volume 3, Issue 4, No. 66, ISSN 2348-5396 (e), ISSN: 2349-3429 (p), DIP:18.01.154/20160304, ISBN: 978-1-365-39396-9 